\title{
Characterization and Evaluation of Antibiotic Susceptibility Pattern of Clinical Isolates of Methicillin Resistant Staphylococcus aureus at Some Tertiary Hospital in Kano, Nigeria
}

\author{
F. S. $\mathrm{Nas}^{1}$, A. Yahaya ${ }^{2}$, A. U. Zage ${ }^{3}$, K. A. Garba ${ }^{4}$ and $*$ M. Ali $^{3}$ \\ ${ }^{l}$ Department of Biological Science, Bayero University Kano \\ ${ }^{2}$ Department of Biological Science, Kano University of Science and Technology Wudil Kano \\ ${ }^{3}$ Microbiology Department, Kano University of Science and Technology Wudil Kano \\ ${ }^{4}$ School of Nursing Madobi, Kano
}

*Corresponding Author: M. Ali, Microbiology Department, Kano University of Science and Technology Wudil Kano, Nigeria.

\begin{abstract}
The problems of microbial resistance to the available antibiotics especially in the hospitals are fast growing and causing a lot of concern. The study was aimed to identify and evaluate antibiotic susceptibility pattern of clinical isolate of methicillin resistant Staphylococcus aureus (MRSA) isolated from wound, HVS and urine sample of patients attending some tertiary hospital in Kano, Nigeria. A total of 107 (37 from wounds and pus, 29 from High vaginal swab (HVS), 41 from urine) suspected clinical isolates of Staphylococcus were collected from the study hospitals over a period of eight months (October, 2015 to May, 2016). Staphylococcus aureus were characterized using conventional microbiological methods: Gram staining, Biochemical test (Coagulase test, Catalase test and DNase test) and Mannitol fermentation test. Disc diffusion method using oxacillin and cefoxitin sensitivity discs were employed for the identification and evaluation of antibiotic susceptibility pattern of MRSA. The results showed that Staphylococcus aureus were able to ferment Mannitol and positive for Catalase, Coagulase and DNase test. MRSA isolates were resistant to beta lactam drugs including both penicillins and cephalosporins. It also showed resistivity to macrolide, and fluroquinolones, but sensitive to tetracycline and aminoglycoside.
\end{abstract}

Keywords: Antibiotics, Methicillin resistant Staphylococcus aureus (MRSA), resistance, susceptibility

\section{INTRODUCTION}

The problems concerning microbial resistance to the available antibiotics especially in the hospitals are fast growing. One of such problem is the emergence of methicillin resistant Staphylococcus aureus (MRSA) which has become a global threat to antimicrobial chemotherapy. The MRSA bacteria belong to the Staphylococcus aureus bacteria family. Staphylococcus aureus is common bacterium which lives harmlessly on the skin and in the nose of around a third of healthy people. When it does cause infection 'ordinary' Staphylococcus aureus is sensitive to most commonly used antibiotics. MRSA is a particular type of Staphylococcus aureus that has developed resistance to several antibiotics. Only a few antibiotics will act against MRSA (Karthy et al., 2009). The wide spread use of antibiotic resulted in the development of resistance to antibiotics through acquisition of the mobile cassette chromosome carrying the Methicillin-resistant gene mecA (Wielders et al., 2002) and mecC (Porrero et al., 2014). Methicillin-Resistant Staphylococcus aureus (MRSA) and Methicillin-Resistant Coagulase-Negative Staphylococci (MR-CoNS) has been identified as multidrug-resistant zoonotic pathogens in humans and many animal species (Morgan, 2008; Barbier et al., 2010). Even through, coagulase negative Staphylococci may also be a normal flora for skin and mucous membranes of human and animal species (Aklilu et al., 2010).

The MRSA was first noted in 1961, about two years after the antibiotic methicillin was initially used to treat Staph aureus and other infectious bacteria. The resistance to methicillin was due to a penicillin-binding protein coded for by a mobile genetic element termed the methicillin-resistance gene - mecA (Diekema and Pfaller, 2000). In recent years, the gene has continued to evolve so that many MRSA strains are currently resistant to several different antibiotics such as penicillin, oxacillin 
and amoxicillin (Muller et al., 2003). MRSA is still considered as an emerging pathogen and public health threats result from the spread of hospital-acquired as well as community-acquired MRSA (Chambers, 2001). The heterogeneous expression of methicillin resistance can make it difficult to determine the resistance phenotype definitively (Frebourg et al., 1998), therefore detection of the mecA gene remains the "gold standard" (Bignardi et al., 1996). The study was aimed to isolate, characterize and evaluate antibiotic susceptibility pattern of methicillin resistant Staphylococcus aureus (MRSA) from 3 selected Hospitals in Kano Metropolis, Nigeria.

\section{Materials AND Methods}

\section{Ethical Approval}

Ethical approval for this research was obtained from the Hospital Service Management Board (HSMB), Kano based on the consent of Murtala Muhammad Specialist Hospital, Sir Muhammad Sunusi Specialist Hospital and Abubakar Imam Urology Centre Ethical Committees.

\section{Study Area}

Clinical isolates of Staphylococcus aureus were obtained from three hospitals within Kano metropolis which include Murtala Mohammed Specialists' Hospital, Sir Muhammad Sunusi Specialists' Hospital and Abubakar Imam Urology centre (MMSH, MSSH and AIUC). Characterization of Staphylococcus aureus and determination of Methicillin resistance Staphylococcus aureus (MRSA) were conducted in the Microbiology Laboratory Kano University of Science and Technology Wudil.

\section{Bacterial Isolation}

\section{Sample collection}

One hundred and seven (107) suspected Staphylococcus isolates were collected from three different hospitals within Kano state metropolis over a period of eight months (October, 2015 to May, 2016). The isolation of Staphylococcus isolates was done by culturing various clinical samples of wounds and pus $(n=37)$, High vaginal swab (HVS) $(n=29)$ and urine $(n=41)$ on a surface of Nutrient agar (Lifesave Biotech, USA). The plates were incubated at $37^{\circ} \mathrm{C}$ for $24 \mathrm{~h}$ for colony formation. Each colony was isolated in a pure form by sub culturing for further studies and identification. Discrete colonies of each isolate were kept in peptone water. The bacterial strains were then stored at $4^{\circ} \mathrm{C}$ for further experiments.

\section{Identification of bacteria}

The isolates were confirmed as Staphylococcus aureus by conventional microbiological methods: Gram staining, Biochemical test (Coagulase test, Catalase test and DNase test) and Mannitol fermentation test

\section{Gram staining}

A drop of normal saline was placed on a well labeled clean grease-free glass slide using a sterile inoculating loop; a colony of an overnight culture of the bacterial isolate was emulsified with the normal saline to make a thin smear. The smear was air dried and then heat fixed. The slide was flooded with crystal violet (primary stain) for 30 seconds after which the stain was rinsed from the slide with water. The smear was flooded with Lugol's iodine (mordant) to fix the primary stain. The iodine was rinsed with water after 60 seconds. The slide was then flooded with a decolorizer (acetone) and rinsed off almost immediately. The counter stain; safranin was added and left for 30 seconds before being rinsed off. The stained smear was air dried, and then observed under the microscope using X100 oil immersion objective lens of the microscope (Cheesbrough, 2006).

\section{Biochemical characterization}

\section{DNase test}

The method as described by Cheesbrough (2006) was used to differentiate Staphylococcus aureus (producer of the enzyme deoxyribonuclease) from other Staphylococci spp. Deoxyribonuclease agar media was prepared and sterilized by autoclaving at $121^{\circ} \mathrm{C}$ for 15 minutes. An overnight broth culture of the organisms was spot inoculated onto agar surfaces of the DNase agar and incubated at $37^{\circ} \mathrm{C}$ for 
18hours. At the end of the incubation period, the agar surface was flooded with $1 \mathrm{~N}$ hydrochloric acid and excess drained off.

\section{Catalase test}

A drop of 3\% hydrogen peroxide was placed on a clean grease-free glass slide. About 2 colonies of the bacteria were picked from a culture plate using a sterile wire loop and placed on the hydrogen peroxide; presence of bubbles observed indicated a positive Catalase test (Holt et al., 1994).

\section{Coagulase test}

Staphylococcus aureus isolates were distinguished from other staphylococci species by the production of Coagulase an enzyme that clots plasma. About one or two drops of blood plasma were placed on a clean grease-free glass slide and 2 colonies of the organism were picked using a sterile wire loop from a $18 \mathrm{~h}$ nutrient agar plate. The colonies were emulsified in the blood plasma and observation of a clot indicated a positive Coagulase test (Holt et al., 1994).

\section{Bacteriological analysis}

The pure colonies on nutrient agar were picked using a sterile inoculating loop and sub-cultured onto the surface of Mannitol Salt Agar (Lifesave Biotech, USA). Then, the plates were incubated at $37^{\circ} \mathrm{C}$ for 24 hours. The changes in color of the medium from pink to yellow indicated positive results.

\section{Identification of Methicillin Resistant Staphylococcus aureus}

All isolates of $S$. aureus (83 isolates) were tested by oxacillin disc diffusion, cefoxitin disc diffusion and oxacillin screen agar test for detection of Methicilin Resistant Staphylococcus aureus (MRSA). Detection of the mecA gene is considered as the reference method for determining methicillin resistance (Chambers, 1997). Resistance of $S$. aureus to oxacillin and/or cefoxitin provides a clue for MRSA suspicion. Oxacillin and cefoxitin test are the preferred method for testing mecA resistant gene of $S$. aureus (CLSI, 2010).

\section{Oxacillin disc diffusion method}

The bacteria suspension adjusted to $0.5 \mathrm{McFarland}$ were subjected to antibiotic susceptibility testing using agar disc diffusion method as described by Bauer et al. (1996). Mueller Hinton agar (MHA) plates were inoculated with overnight culture of each isolate by streak plating. The $1 \mu \mathrm{g}$ oxacillin sensitivity discs (Hi-Media) were then aseptically placed at equidistance on the plates and allowed to stand for 1 hour. The plates were then incubated at $37^{\circ} \mathrm{C}$ for 24 hours. Sensitivity pattern of the isolates to oxacillin discs based on zones of produced. Zone of inhibition was interpreted according to CLSI (2010) criteria: susceptible, $>13 \mathrm{~mm}$; intermediate, 11-12 mm; and resistant $<10 \mathrm{~mm}$ (Swenson et al., 2001). A commercially prepared antibiotic disc containing $10 \mu \mathrm{g}$ clindamycin was used as positive control.

\section{Cefoxitin disc diffusion method}

The bacteria suspension adjusted to $0.5 \mathrm{McFarland}$ were subjected to antibiotic susceptibility testing using agar disc diffusion method as described by Bauer et al. (1996). Mueller Hinton agar (MHA) plates were inoculated with overnight culture of each isolate by streak plating. The $30 \mu \mathrm{g}$ cefoxitin sensitivity discs (Hi-Media) were then aseptically placed at equidistance on the plates and allowed to stand for 1 hour. The plates were then incubated at $37^{\circ} \mathrm{C}$ for 24 hours. Sensitivity pattern of the isolates to cefoxitin discs based on zones of produced. Zone of inhibition was interpreted according to CLSI (2010) criteria: susceptible, $>13 \mathrm{~mm}$; intermediate, 11-12 mm; and resistant $<10 \mathrm{~mm}$ (Swenson et al., 2001).

\section{Oxacillin screen agar test.}

A bacterial inoculum of each strain was made and turbidity was adjusted to $0.5 \mathrm{McFarland}$. One drop of this suspension was inoculated on Mueller-Hinton agar containing $4 \% \mathrm{NaCl}$ and $6 \mathrm{mg}$ oxacillin per $\mathrm{ml}$ (Hi-Media). Plates were incubated at $37{ }^{\circ} \mathrm{C}$ for $24 \mathrm{~h}$. Any strain showing growth on the plate containing oxacillin was considered to be resistant to methicillin (Swenson et al., 2001). 


\section{Antibiotic Susceptibility Test}

The MRSA isolates were subjected to antibiotic susceptibility testing using the agar disc diffusion method as described by Bauer et al. (1996). Mueller Hinton agar (MHA) plates were inoculated with overnight culture of each isolate by streak plating. The standard antibiotic sensitivity discs were then aseptically placed at equidistance on the plates and allowed to stand for 1 hour. The plates were then incubated at $37^{\circ} \mathrm{C}$ for 24 hours. Sensitivity pattern of the isolates to Erythromycin $(10 \mu \mathrm{g} / \mathrm{disc})$, Ampicillin $(30 \mu \mathrm{g} / \mathrm{disc})$, Gentamicin $(10 \mu \mathrm{g} / \mathrm{disc})$, Doxycycline $(30 \mu \mathrm{g} / \mathrm{disc})$ and Ciprofloxacin (30 $\mu \mathrm{g} / \mathrm{disc}$ ) produced by Abtek pharmaceutical limited, were determined. Isolates were divided into three groups based on the zone of inhibition produced by the antibiotic disc; susceptible, intermediately susceptible and resistant according to the Clinical and Laboratory Standards Institute (CLSI) guideline (CLSI, 2010).

\section{RESUlT AND DISCUSSION}

\section{Identification of Staphylococcus aureus}

The biochemical and confirmatory tests for identification of Staphylococcus aureus is presented in table 1. Isolates were subjected to Gram staining, Mannitol fermentation and Catalase, Coagulase and DNase tests. Based on the results of the tests, 83 out of the 107 isolates were found to be Staphylococcus aureus. Highest number of S. aureus was recorded in wound isolates (41) while 29 and 37 were recorded in HVS and Urine isolates respectively.

Table 1. identification off Staphylococcus aureus from the suspected samples

\begin{tabular}{|c|c|c|}
\hline Isolate source & No. of suspected S. aureus & No. of Confirmed S. aureus \\
\hline Wound and pus & 37 & 35 \\
\hline High vaginal swab & 29 & 23 \\
\hline Urine & 41 & 25 \\
\hline Total & $\mathbf{1 0 7}$ & $\mathbf{8 3}$ \\
\hline
\end{tabular}

\section{Identification of Methicillin resistant Staphylococcus aureus (MRSA)}

Isolates were tested using oxacillin disc diffusion, cefoxitin disc diffusion and oxacillin screen agar test for detection of MRSA. Out of a total of 83 isolates of Staphylococcus aureus, only 8 (15\%) strains were found to be Methicillin resistant Staphylococcus aureus (MRSA). Clinical samples with highest number of MRSA strains isolated is wound (5), followed by urine (2), and HVS (1). The total number of MRSA strains isolated from the clinical samples is represented in Table 2

Table 2. Identification of Methicillin resistant Staphylococcus aureus (MRSA)

Antibiotics/zone of inhibition (mm)

\begin{tabular}{|c|c|c|c|c|c|}
\hline $\begin{array}{l}\text { Isolate } \\
\text { code }\end{array}$ & $\begin{array}{r}\text { Oxacillin } \\
\text { disc }(1 \mu \mathrm{g})\end{array}$ & $\begin{array}{c}\text { Cefoxitin } \\
\text { disc }(30 \mu g)\end{array}$ & $\begin{array}{c}\text { Oxacillin } \\
\text { agar }\end{array}$ & $\begin{array}{c}\text { Clindamycin } \\
\text { disc }(10 \mu \mathrm{g})\end{array}$ & Status \\
\hline $\mathrm{W}_{4}$ & 10 & 06 & 06 & 17 & MRSA \\
\hline $\mathrm{W}_{11}$ & 06 & 06 & 06 & 15 & MRSA \\
\hline $\mathrm{W}_{17}$ & 06 & 08 & 06 & 18 & MRSA \\
\hline $\mathrm{W}_{18}$ & 08 & 10 & 06 & 17 & MRSA \\
\hline $\mathrm{W}_{23}$ & 06 & 10 & 06 & 18 & MRSA \\
\hline $\mathrm{H}_{9}$ & 10 & 08 & 06 & 19 & MRSA \\
\hline $\mathrm{U}_{5}$ & 08 & 08 & 06 & 21 & MRSA \\
\hline $\mathrm{U}_{19}$ & 10 & 06 & 06 & 19 & MRSA \\
\hline
\end{tabular}

Key W = Wound, H = HVS, U = Urine, MRSA = Methicillin resistant Staphylococcus aureus, $06=$ No zone of inhibition.

\section{Antibiotic Susceptibility Test}

Antibiotic Susceptibility test was carried out for the 83 S. aureus isolates, and the zones of inhibition obtained were classified based on clinical and laboratory standards institute (2012) in Tables 3. The result of antibiotic Susceptibility testing showed that most of the MRSA isolates were resistant to the beta - lactam antibiotic (Ampicillin), Macrolide (Erythromycin) and fluroquinolone (Ciprofloxacin). On the other hand, they found sensitive to Tetracyline (Doxycycline) and Aminoglycoside (Gentamicin) 
Characterization and Evaluation of Antibiotic Susceptibility Pattern of Clinical Isolates of Methicillin Resistant Staphylococcus aureus at Some Tertiary Hospital in Kano, Nigeria

Table 3. Zone of inhibition of recovered MRSA strains against selected antibiotics

Antibiotics/zones of inhibition (mm)

\begin{tabular}{|c|c|c|c|c|c|}
\hline Isolate code & $\begin{array}{c}\text { Ery } \\
(\mathbf{1 0} \boldsymbol{\mu g})\end{array}$ & $\begin{array}{c}\text { Dox } \\
(\mathbf{3 0} \boldsymbol{\mu g})\end{array}$ & $\begin{array}{c}\text { Amp } \\
(\mathbf{1 0} \boldsymbol{\mu g})\end{array}$ & $\begin{array}{c}\text { Cip } \\
(\mathbf{3 0} \boldsymbol{\mu g})\end{array}$ & $\begin{array}{c}\text { Gen } \\
(\mathbf{1 0} \boldsymbol{\mu g})\end{array}$ \\
\hline $\mathrm{W}_{4}$ & 09 & 15 & 09 & 10 & 15 \\
\hline $\mathrm{W}_{11}$ & 08 & 17 & 06 & 06 & 16 \\
\hline $\mathrm{W}_{17}$ & 06 & 18 & 10 & 10 & 13 \\
\hline $\mathrm{W}_{18}$ & 06 & 13 & 06 & 08 & 18 \\
\hline $\mathrm{W}_{23}$ & 09 & 17 & 10 & 10 & 18 \\
\hline $\mathrm{H}_{9}$ & 10 & 19 & 09 & 10 & 19 \\
\hline $\mathrm{U}_{5}$ & 06 & 21 & 06 & 10 & 15 \\
\hline $\mathrm{U}_{19}$ & 06 & 21 & 06 & 08 & 04 \\
\hline
\end{tabular}

Key $\mathrm{W}=$ Wounds isolates, $\mathrm{H}=\mathrm{HVS}$ isolates, $\mathrm{U}=$ Urine isolates, Ery = Erythromycin, Dox = Doxycycline, Amp = Ampicillin, Cip = Ciprofloxacin, Gen = Gentamicin

\section{Antibiotic Susceptibility pattern}

The antibiotic susceptibility pattern of the isolates against selected antibiotic is presented in table 4. Antibiotic susceptibility pattern of the isolate was classified as susceptible (S), intermediately susceptible (I) and resistant (R) based on the zone of inhibition produced by isolates against the antibiotics.

Table 4. Antibiotic Susceptibility pattern of the test isolates against selected antibiotics

\section{Antibiotics/zones of inhibition (mm)}

\begin{tabular}{|c|c|c|c|c|c|}
\hline Isolate code & $\begin{array}{c}\text { Ery } \\
(\mathbf{1} \boldsymbol{\mu g})\end{array}$ & $\begin{array}{c}\text { Dox } \\
(\mathbf{3 0} \boldsymbol{\mu g})\end{array}$ & $\begin{array}{c}\text { Amp } \\
(\mathbf{1 0} \boldsymbol{\mu g})\end{array}$ & $\begin{array}{c}\mathbf{C i p} \\
(\mathbf{3 0} \boldsymbol{\mu g})\end{array}$ & $\begin{array}{c}\text { Gen } \\
(\mathbf{1 0} \boldsymbol{\mu g})\end{array}$ \\
\hline $\mathrm{W}_{4}$ & $\mathrm{R}$ & $\mathrm{S}$ & $\mathrm{R}$ & $\mathrm{R}$ & $\mathrm{S}$ \\
\hline $\mathrm{W}_{11}$ & $\mathrm{R}$ & $\mathrm{S}$ & $\mathrm{R}$ & $\mathrm{R}$ & $\mathrm{S}$ \\
\hline $\mathrm{W}_{17}$ & $\mathrm{R}$ & $\mathrm{S}$ & $\mathrm{R}$ & $\mathrm{R}$ & $\mathrm{I}$ \\
\hline $\mathrm{W}_{18}$ & $\mathrm{R}$ & $\mathrm{I}$ & $\mathrm{R}$ & $\mathrm{R}$ & $\mathrm{S}$ \\
\hline $\mathrm{W}_{23}$ & $\mathrm{R}$ & $\mathrm{S}$ & $\mathrm{R}$ & $\mathrm{R}$ & $\mathrm{S}$ \\
\hline $\mathrm{H}_{9}$ & $\mathrm{R}$ & $\mathrm{S}$ & $\mathrm{R}$ & $\mathrm{R}$ & $\mathrm{S}$ \\
\hline $\mathrm{U}_{5}$ & $\mathrm{R}$ & $\mathrm{S}$ & $\mathrm{R}$ & $\mathrm{R}$ & $\mathrm{S}$ \\
\hline $\mathrm{U}_{19}$ & $\mathrm{R}$ & $\mathrm{S}$ & $\mathrm{R}$ & $\mathrm{R}$ & $\mathrm{S}$ \\
\hline
\end{tabular}

Key $\mathrm{W}=$ Wounds isolates, $\mathrm{H}=$ HVS isolates, $\mathrm{U}=$ Urine isolates, Ery = Erythromycin, Dox = Doxycycline, Amp = Ampicillin, Cip = Ciprofloxacin, Gen = Gentamicin, $\mathrm{R}=$ Resistant, $\mathrm{I}=$ Interediate, $\mathrm{S}=$ Susceptible

This study was aimed to identify and evaluate antibiotic susceptibility pattern of clinical isolate of MRSA isolated from wound, HVS and urine sample of patients attending some tertiary hospital in Kano, Nigeria. Identification of Staphylococcus aureus was based on cultural characteristics, Gram staining and biochemical properties. A total of 107 isolates were collected out of which 83 were able to ferment Mannitol with the color change of Mannitol Salt Agar (MSA) and produced yellow colony. Gram-stained smears of the pure cultures exhibited clusters of Gram-positive cocci. These isolates were positive for Catalase, Coagulase test and DNase test. In Catalase test, Hydrogen peroxide was broken-down into water and oxygen. Production of oxygen was indicated by bubble formation (Jahan et al., 2015). The isolates were also identified as $S$. aureus by Coagulase test. The positive result of Coagulase test was confirmed by the formation of curd like clotting compared to negative control (Jahan et al., 2015). Earlier findings by Amengialue et al. (2013); Yabaya et al. (2011); Jahan et al. (2015) and Stanley et al. (2013) identified and characterized Staphylococcus aureus on the basis of cultural characteristics, Gram staining and Biochemical characterization.

In the present research, MRSA was detected using Oxacillin and Cefoxitin sensitivity disc using Kirby Bauer disc diffusion method and oxacillin screen agar test, the results of resistivity test for detection of Methicillin Resistance Staphylococcus aureus (MRSA) shows that a total of eight samples were found to be MRSA. Highest samples were found in wound isolate with total of 5 while 2 and 1 samples were found among Urine and HVS samples respectively. Higher number of Methicillin Resistance Staphylococcus aureus (MRSA) in wound is due to the fact that the organisms colonize human skin tissue. A gene known as mecA gene is responsible for the resistance to methicillin which codes for penicillin-binding protein PBP 2A (Wielders et al., 2002). Lately, a new 
methicillin resistance mechanism gene, mecC was described in S. aureus (Porrero et al., 2014). García-Álvarez et al. (2011), Paterson et al. (2012), Walther et al. (2012) and Paterson et al. (2014) reported MRSA isolates carrying mec $\mathrm{C}$ gene from humans and animals. Harrison et al. (2013) suggested the public health hazard of mecC-positive MRSA isolates as it has been isolated in human case and their livestock. The wide spread use of antibiotic resulted in the development of resistance to antibiotics through acquisition of the mobile cassette chromosome carrying the methicillin-resistant gene mecA (Wielders et al., 2002) and mecC (Porrero et al., 2014). The resistance to methicillin was due to a penicillin-binding protein coded for by a mobile genetic element termed the methicillinresistance gene - mecA (Diekema and Pfaller, 2000). In recent years, the gene has continued to evolve so that many MRSA strains are currently resistant to several different antibiotics such as penicillin, oxacillin and amoxicillin (Muller et al., 2003).

The result of antibiotic Susceptibility testing showed that the MRSA isolates were resistant to the beta - lactam antibiotic (Ampicillin), Macrolide (Erythromycin) and fluroquinolone (Ciprofloxacin). On the other hand, they found sensitive to Tetracyline (Doxycycline) and Aminoglycoside (Gentamicin). The organisms have ability to grow in the presence of beta lactam drugs such as penicillins and cephalosporins. The result of this study was inconformity with the assertion of Karthy et al. (2009) who explained MRSA as serious threat due to its ability of resistance to multiple antibiotics. They further explained that several antibiotics such as penicillin, macrolides, fluroquinolones and lincosamide were found resistant and ineffective against MRSA. Presently, less than $90 \%$ of S. aureus strains are resistant to most penicillin derivatives and ordinary antimicrobial agents like drugs from the family of aminoglycosides, macrolides, chloramphenicols and fluoroquinolones (Lee, 2003). Most antibiotics used for treatment of MRSA infection has been reported to have developed resistance (Ayliffe, 1997). Antibiotics such as trimethoprim-sulphamethoxazole, clindamycin and doxycycline are reported to be effective in the treatment of CA-MRSA infection (Ernst, 2012).

\section{CONClusion}

The findings of this study revealed that Staphylococcus aureus are Gram positive cocci, positive for Catalase, Coagulase and DNase tests. They are also able to ferment Mannitol with formation of Golden yellow color. MRSA were found to be resistant to resistant to oxacillin and cefoxitin sensitivity disc. The study revealed that MRSA was multi drug resistant isolate, showing resistivity to various class of antibiotics such as macrolide, fluroquinolones and cephalosporins.

\section{ACKNOWLEDGEMENT}

The authors are grateful to entire staff of Microbiology Department of Kano University of Science and Technology Wudil for provision of reagents and use of laboratory facilities. Thanks to Kano State Government through Health Service Management Board for granting us with ethical clearance.

\section{REFERENCES}

Aklilu, E., Zunita, Z., Hassan, L., Chen, H.C. (2010). Phenotypic and genotypic characterization of methicillinresistant Staphylococcus aureus (MRSA) isolated from dogs and cats at university veterinary hospital, Universiti Putra Malaysia. Trop. Biomed., 27(3): 483-492.

Amengialue, O. O., Osawe, F. O., Edobor, O., Omoigberale, M. N. O., Egharevba, A. P. (2015). Prevalence and antibiogram pattern of Staphylococcus aureus in urinary tract infection among patients attending specialist hospital, Benin City, Nigeria. G.J.B.A.H.S. 2(4):46-49.

Ayliffe, G. (1997). The progressive intercontinental spread of methicillin-resistant Staphylococcus aureus. Clin. Infec. Dis. 24 (1): 74-79. http://dx.doi. org/10.1093/clinids/24.Supplement_1.S74

Bauer AW, Kirby WM, Sherris JC, and Turck M Antibiotic susceptibility testing by a standardized single disk method. Am J Clin Pathol 1966; 45: 493-496.

Bignardi, G. E., Woodford, N., Chapman, A., Johnson, A. P. and Speller, D. C. (1996). Detection of the mecA gene and phenotypic detection of resistance in Staphylococcus aureus isolates in borderline or low-level methicillin resistance. J. Antimicrob. Chemother., 37: 53-63.

Chambers, H. F. (2001). The changing epidemiology of Staphylococcus aureus. Emerg. Infect. Dis., 7: 178-182.

Chessbrough M. 2006. District laboratory practice in tropical countries, second edition, part two, Cambridge university press. Examination of pus, ulcer material and skin specimens.2006; pp 80-85

CLSI, (2010)."Performance standards for antimicrobial susceptibility testing," Twentieth informational supplement, Clinical and Laboratory Standards Institute Doc. M100eS20, 2010. 
Diekema, D.J., Pfaller, M.A., Schmitz, F.J., Smayevsky, J., Bell, J., Jones, R. N.and Beach, M. (2001). Survey of infections due to Staphylococcus species: frequency of occurrence and antimicrobial susceptibility of isolates collected in the United States, Canada, Latin America, Europe, the Asia.

Ernst, J. (2012). Managing CA-MRSA. Dermatol. 20 (3). http://www.the-dermatologist.com/content/ managingca-mrsa, accessed in 10 December 2014.

Frebourg, N. B., Nouet, D., Lemee, L., Martin, E. and Lemeland, J. F. (1998). Comparison of ATB Staph, Rapid ATB Staph, Vitek and E-test methods for detection of oxacillin hetero resistance in staphylococci possessing mecA. J. Clin. Microbiol., 36: 52-57.

García-Álvarez, L., Holden, M. T., Lindsay, H., Webb, C. R., Brown, D. F., Curran, M. D. (2011). Meticillinresistant Staphylococcus aureus with a novel mecA homologue in human and bovine populations in the UK and Denmark: a descriptive study. Lancet Infect. Dis. 11(8): 595-603. http://dx.doi.org/10.1016/ S1473- 3099(11)70126-8

Harrison, E. M., Paterson, G. K., Holden, M. T. G., Morgan, F. J. E., et al. (2013). A Staphylococcus xylosus Isolate with a New mecC Allotype. Antimicrob. Agents Chemother. 57(3): 1524-1528. http://dx.doi. org/10.1128/AAC.01882-12

Holt JG, Krieg NR, Sneath PA, Stanley JT and Williams ST (1994). Bergey's manual of systematic bacteriology, 9th edition. Williams \& Wilkins Co. Baltimore, Maryland, p786

Jahan, M, Rahman, M, Parvej, S, Shah, M., Chowdhury, Z. H., Haque, M. (2005). Isolation and characterization of Staphylococcus aureus from raw cow milk in Bangladesh. J. Adv. Vet. Anim. Res. 2(1):49-55.

Karthy, E.S., Ranjitha, P., and Mohankumar, A. (2009): Antimicrobial Potential of Plant Seed Extracts against Multidrug Resistant Methicillin Resistant Staphylococcus aureus (MDR-MRSA). International J. of Biology, 1(1):

Lee, J. H. (2003). Methicillin (Oxacillin)-resistant Staphylococcus aureus strains isolated from major food animals and their potential transmission to humans. Appl. Environ. Microbiol. 69(11): 6489-6494. http://dx.doi.org/10.1128/AEM.69.11.6489-6494.2003 PMid:14602604 PMCid:PMC262320

Muller, A.A., Mauny, F., and Bertin, M. (2003). Relationship between spread of MRSA and antimicrobial use in a French university hospital. Clin Infect Dis., 36:971-978.

Paterson, G. K., Larsen, A. R., Robb, A., Edwards, G. E., Pennycott, T. W., Foster, G. (2012). The newly described mecA homologue, mecALGA251, is present in methicillin-resistant Staphylococcus aureus isolates from a diverse range of host species. J. Antimicrob. Chemother. 67(12): 2809-2813. DOIPubMed http://dx.doi.org/10.1093/jac/dks329 PMid: 22941897 PMCid:PMC3494845

Porrero, M.C., Harrison, E., Fernandez-Garayzabal, J.F., Paterson, G.K., Diez-Guerrier, A., Holmes, M.A., and Dominguez, L. (2014). Detection of mecC-MRSA isolates in river water: A potential role for water in the environmental dissemination. Environ. Microbiol. Rep.,

Stanley, C. N., Ugboma, H., Ibezim, E. and Attama, A. (2015): Prevalence and Antibiotic Susceptibility of Staphylococcus aureus and Other Staphylococcal Infections in Pregnant Women Attending Antenatal Clinic in a Tertiary Hospital in Port Harcourt, Nigeria. J Infec. Disease and therapy 2:1

Swenson, J. M., Williams, P. P., Killgore, G., O’Hara, C. M. \& Tenover, F. C. (2001). Performance of eight methods, including two new rapid methods, for detection of oxacillin resistance in a challenge set of Staphylococcus aureus organisms. J Clin Microbiol. 39, 3785-3788.

Wielders, C.L.C., Fluit, A.C., Brisse, S., Verhoef, J., and Schmitz, F.J. (2002). mecA gene is widely disseminated in Staphylococcus aureus population. J. Clin., 40(11): 3970-3975.

Yabaya, A., Jeremiah, M. Y, Manga, S. S, Umar, A. (2011). Prevalence and antimicrobial susceptibility pattern of Staphylococcus aureus isolated from the skin and Nasal cavity of students and staff of Kaduna state University, Kaduna, Nigeria. Best Journal. 8(2):191-194.

Citation: F. S. Nas et al., "Characterization and Evaluation of Antibiotic Susceptibility Pattern of Clinical Isolates of Methicillin Resistant Staphylococcus aureus at Some Tertiary Hospital in Kano, Nigeria ", International Journal of Research studies in Microbiology and Biotechnology, vol. 4, no. 2, p. 38-44, 2018. http://dx.doi.org/10.20431/2454-9428.0402004

Copyright: (C) 2018 F. S. Nas et al., This is an open-access article distributed under the terms of the Creative Commons Attribution License, which permits unrestricted use, distribution, and reproduction in any medium, provided the original author and source are credited. 